\title{
CONTROLE DE MUSCA DOMESTICA LINNAEUS \\ (DIPTERA, MUSCIDAE) EM ÁREA DE MANEJO DE VINHAÇA (MACATUBA, SÃO PAULO, BRASIL)
}

GERALDO MAGELA BURALLI ${ }^{1}$ JOSÉ HENRIQUE GUIMARÃES 2

\begin{abstract}
Refuse from sugar and alcohol industries is rich in organic matter, offering an ideal breeding ground for house-flies. This pest breeds in countless numbers in such substrate, causing severe outbreaks in several counties of the State of São Paulo, Brazil. To control the nuisance, the formula: borax $\left(\mathrm{Na}_{2} \mathrm{~B}_{4} \mathrm{O}_{7}\right)$ and slaked lime $\left(\mathrm{Ca}(\mathrm{OH})_{2}\right)$ solutions of $3.18 \%$ and $0.35 \%$, respectively, were applied at the channels carrying the waste waters from the alcohol refinery at intervals of 10-15 days. With this method, a very satisfactory control of house-fly populations was obtained at Macatuba, São Paulo, Brazil, between July 1981 and April 1982.
\end{abstract}

\section{INTRODUÇÃO}

A vinhaça, também conhecida como vinhoto, restilo ou garapão, é o principal resíduo da fabricação do álcool, tanto pelo grande volume produzido, como pela sua ação poluidora potencial.

Considera-se que a produção de 1 litro de álcool gera em média 15 litros de vinhaça. Nos últimos anos tem crescido o interesse pelo destino dado a esse resíduo, em virtude, principalmente, da constatação do seu valor como fert:lizante da lavoura de cana-de-açúcar, podendo interferir sensivelmente na economia do setor (Glória, 1977; Copersucar, 1980; Governo do Estado de São Paulo, 1980).

Nos últimos cinco anos, generalizou-se no Estado de São Paulo uma nova prática agrícola: a aplicação de vinhaça ao solo. Essa prática, se por um lado pode resolver o problema da poluição das coleções hídricas pela descarga de vinhaça, por outro pode gerar uma outra forma de poluição ambiental - a proliferação de moscas. Dependendo da forma como a vinhaça é utilizada na lavoura, pode-se dar origem a grandes extensões de solo excessivamente impregnados do resíduo, formando um ambiente muito propício à criação de moscas, particularmente Musca domestica.

Embora se disponha na literatura científica de escassas referências a um problema que existe há pelo menos cinco anos no Brasil, pode-se notar a partir de 1981 a preocupação crescente de populações urbanas com o aumento da proliferação de moscas, através da imprensa (Capozoli, 1981; Anon., 1981).

Algumas empresas, por sua vez, têm-se preocupado com a elevada população de moscas que frequienta as instalações da usina no verão, principalmente devido à atração que exercem as instalações de acondicionamento do açúcar. Entretanto, mesmo nestas usinas que já se ocuparam do problema, as tentativas de controle têm sido tímidas em função, provavelmente, de dois fatores: 1. o custo elevado dos inseticidas e equipamentos, junto à ineficácia observada da maioria dos larvicidas no meio solo/vinhaça; 2. o risco de, usando inseticidas contra os insetos adultos no ambiente, alterar o controle biológico da broca da cana feito por moscas da família Tachinidae. O con-

1. Superintendência de Controle de Endemias, Secretaria da Saúde do Estado de São Paulo.

2. Museu de Zoologia, Universidade de São Paulo. Bolsista do Consəlho Nacional de Desenvolvimento Científico e Tecnológico. 
trole da broca, por afetar diretamente a produtividade, é prioritário para as empresas no controle das pragas.

No entanto, mesmo que a utilização de inseticidas se mostrasse eficaz e passasse a ser usado sistematicamente, esbarraria provavelmente no desenvolvimento da resistência aos inseticidas. No caso de Musca domestica, esse processo é particularmente rápido e pode ser avaliado pelo grande número de experimentos publicados constatando a resistência dessa espécie à quase totalidade dos inseticidas conhecidos (West \& Peters, 1973).

Com base nestas dificuldades e dentro da perspectiva de encontrar uma solução do problema capaz de ser assumido pila empresa, iniciou-se um projeto visando adaptar formas simples de controle de larvas já utilizadas com sucesso em outros tipos de criadouros. A avaliação de uma tentativa preliminar, mas com resultados favoráveis, é o objeto deste trabalho.

\section{MATERIAL E MÉTODO}

Este trabalho foi realizado na área da Usina São José, município de Macatuba, Estado de São Paulo, no período de julho de 1981 a abril de 1982 . Essa empresa apresenta uma área cultivada de 40.000 hectares de cana-deaçúcar e produz álcool pelo sistema de destilaria anexa. Toda a vinhaça decorrente da produção do álcool é utilizada na fertirrigação da lavoura, principalmente soqueiras, por um sistema de bicos de aspersão. A distribuição da vinhaça até os pontos de aplicação é feita por uma rede de canais que desembocam em cinco grandes poços que alimentam bombas de recalque do resíduo para quotas superiores do terreno. Esses canais e poços são permanentes e vão alimentar uma rede de canais secundários, abertos segundo a orientação das áreas a serem irrigadas. Os poços medem cerca de $100 \mathrm{~m}$ de comprimento por $10 \mathrm{~m}$ de largura e $5 \mathrm{~m}$ de profundidade, cada um. A rede de canais principais e secundários soma cerca de $18 \mathrm{~km}$ de comprimento, com largura média de 2 metros.

Os criadouros de moscas se instalam nas margens e leito dos poços e canais, em áreas que estão sofrendo um processo de secagem.

Em cada mês se trabalhou durante uma semana na área, colhendo informações sobre a evolução desses criadouros. Foram utilizadas amostras de solo impregnado, de $10 \mathrm{~cm}^{3}$ de volume, tomadas do estrato superficial e do estrato imediatamente seguinte, ou seja, porções do solo até 10 e $20 \mathrm{~cm}$ de profundidade. Em cada bloco foi determinado o teor de umidade, pela diferença entre peso úmido e seco, número e espécie de larva presente e $\mathrm{pH}$.

Concomitantemente, foram feitas medidas da densidade de moscas adultas numa área central da Usina, em seis pontos fixos, próximos aos criadouros mais expressivos, através de armadilhas com iscas. Cada armadilha constou de uma lata de $1.000 \mathrm{ml}$ (lata de leite em pó) com perfurações na base, um funil de tela fina com o diâmetro maior apoiado na abertura da lata e um recipiente de vidro de $10 \times 10 \mathrm{~cm}$ emborcado sobre este conjunto. A cada 15 minutos, a parte superior desta era trocada por um conjunto limpo, enquanto o recipiente contendo as moscas era colocado sobre algodão embebido em clorofórmio. As iscas utilizadas foram aquelas que se mostraram mais atrativas nos testes preliminares, a saber: vísceras de galinha, fezes humanas e leite em pó.

A densidade de moscas foi expressa pelo número total de exemplares capturados num período de 8 horas de trabalho.

\section{Medidas de Controle}

O tratamento dos criadouros foi feito inicialmente com a aplicação de cal (hidróxido de cálcio) em pó e em solução sobre os canais. Posteriormente aplicou-se uma solução de cal a 3,18\% (2,5 Bé) acrescida de bórax (tetraborato de sódio) a $0,35 \%$. Essa mistura foi aplicada à razão de 5 litros por $\mathrm{m}^{2}$, com intervalos de 10 a 15 dias, utilizando-se uma bomba acoplada a um caminhão-tanque. 
Formações dos Criadouros

As observações a seguir se referem a Musca domestica, que representou mais de $90 \%$ dos exemplares capturados.

Conforme já se mencionou anteriormente, os criadouros de larvas se instalam nas margens e leitos dos canais. Observou-se que essa instalação depende da quantidade de vinhaça retida pelo solo e do teor de umidade existente, pois não se encontraram larvas na área irrigada por aspersão, com dosagens entre 30 e $60 \mathrm{~m}^{3}$ de vinhaça por hectare. A umidade ideal para o criadouro parece estar entre 20 a $30 \%$.

A distribuição das larvas no substrato não é homogênea. Em geral ocorrem áreas de alta densidade, rodeadas por faixas de densidade menor. Nos pontos de maior concentração encontrou-se uma média de 960 larvas por decímetro cúbico e substrato, na porção superficial. Verticalmente a densidade diminuiu com a profundidade, de forma que, a $20 \mathrm{~cm}$, encontrou-se apenas $5 \%$ daquela superficial.

As variações sazonais na densidade de larvas e, posteriormente, na de adultos, estão relacionadas principalmente às modificações que ocorrem nos criadouros com o desenvolvimento da safra, a elevação da temperatura e o regime de chuvas.

Os criadouros começam a aparecer já no início da moagem, ainda sob o efeito das baixas temperaturas. Nos meses de julho e agosto encontrou-se uma densidade baixa de moscas adultas em virtude de dois fatores principais: 1) apenas uma faixa de terra impregnada de vinhaça oferece condições para o crescimento das larvas, já que o leito dos canais está coberto por vinhaça líquida (o excesso de umidade é um dos principais fatores limitantes para $M$. domestica); 2) a oscilação da vazão do líquido inunda periodicamente essa faixa de criadouro marginal, matando as larvas por afogamento. Grande quantidade de larvas mortas é retida nas peneiras que filtram a vinhaça na entrada das bombas de recalque.

A faixa marginal de criadouros tem cerca de 10 a $20 \mathrm{~cm}$ de largura e acompanha toda a extensão dos canais e poços. Apresentam uma coloração escura, devido à oxidação da vinhaça e ao acúmulo de cápsulas pupais de $M$. domestica que se acumulam na superfície. Com o decorrer da safra, o problema se agrava à medida que os canais secundários vão sendo inativados ou o são temporariamente para atender à fertirrigação rotativa das áreas de cultivo. O aumento do número de canais inativos coincide com a elevação da temperatura nos meses finais de safra, fazendo com que os criadouros aumentem em área pela generalização das zonas de solo impregnado que vão sofrendo o enxugamento necessário para permitir o desenvolvimento larval. A ampliação dos criadouros evolui rapidamente a partir do final de setembro, até o término da moagem, na $2 .^{a}$ quinzena de novembro.

Nos meses quentes de entre-safra, além da faixa marginal de criadouros, que se alargou consideravelmente, e dos canais secundários, tem-se ainda a condensação e secagem da vinhaça que ficou retida nos canais principais e poços de reserva, que passam a apresentar condições favoráveis à criação de moscas. Observa-se que uma camada superficial de aproximadamente $5 \mathrm{~cm}$ sofre dessecamento e rachaduras, isolando pequenos blocos de material quase seco, abaixo da qual está a vinhaça pastosa, não misturada à terra. Sob estas crostas os ovos de moscas, colocados em massa, encontram umidade suficiente para eclosão e as larvas, em conjunto, promovem a aeração necessária do material pastoso, através do cavamento de pequenos túneis.

Uma vez que neste período não existe o fluxo de vinhaça líquida, a umidade dos criadouros fica sujeita ao regime de chuvas. A pluviosidade moderada e regular dos meses de verão impede o dessecamento excessivo dos criadouros. Entretanto, esta situação se modifica quando ocorrem chuvas pesadas, acima de $70 \mathrm{~mm}$ no dia, capazes de encher os canais. Neste caso 
ocorre elevada mortalidade-de larvas por afogamento, verificada pela camada de larvas mortas que flutuam, cobrindo a superfície do canal nos dias seguintes à cheía. Nos canais com facilidade de drenagem, e dependendo do intervalo entre as chuvas, pode ocorrer o rebaixamento rápido da água com a deposição dessa camada de larvas mortas na superfície da lama que forra o canal. Sob ação do sol, reinicia-se o processo já descrito de enxugamento da matéria orgânica, acrescida da densa camada de larvas mortas, que inicim processo de decomposição. Esta situação parece ser particularmente atraente para as moscas adultas, pois nota-se intensa oviposição tanto de $M$. domestica como califorídeos do gênero Chrysomya (moscas "varejeiras").

Nos poços de bombeamento e certos trechos do canal principal a secagem é retardada, visto o grande volume de água que se acumula. A secagem nestes casos é lenta, repetindo-se a formação da faixa de foco marginal que progride lentamente para o centro. A inundação dos canais funciona como um regulador periódico da densidade de moscas, pela mortalidade das larvas e por impedir durante certo tempo novas oviposições. No entanto, essa situação dificilmente ultrapassa uma quinzena. Observou-se que, 20 dias após uma chuva forte, os canais já apresentam intensa atividade larvária.

\section{Tentativas de Controle}

As variações observadas na população de $M$. domestica estão representadas na Figura 1, onde estão sobrepostos também os principais fatores que afetam essas variações, quais sejam: as temperaturas mínimas e máximas, a pluviosidade diária e as datas das aplicações do tratamento.

O grande aumento na população de moscas adultas se dá a partir da $1 .^{\mathrm{a}}$ quinzena de outubro, quando os valores ao redor de 1.000 exemplares capturados por dia sobem ao redor de 30.000. Espera-se que, observando a evolução dos criadores e com base na experiência da empresa nos anos anteriores, no período de outubro a março a densidade se mantenha alta, com variações devidas provavelmente às grandes chuvas. A partir desse mês e início de abril é feita a limpeza das valas e tanques para a próxima safra, destruindo os criadouros, ao mesmo tempo em que a temperatura começa a baixar, dando início então ao período de baixa densidade de moscas, que caracteriza o início da moagem. No entanto, observou-se uma redução sensível na densidade de mosca já a partir de novembro e mais acentuada a partir de janeiro, seguramente como resposta ao período de intenso combate larval que se iniciou na $1 .^{\mathrm{a}}$ quinzena de novembro e se manteve durante $o$ mês de dezembro.

Inicialmente procurou-se apenas alterar sensivelmente o $\mathrm{pH}$ dos criadouros, através da adição de cal aos canais, como forma de dificultar o crescimento larvário. $\mathrm{O}$ estudo do $\mathrm{pH}$ de várias amostras mostrou que variava entre 6,5 e 8,5 nos criadouros em atividade. Os ensaios de laboratório mostraram que a adição de cal ao vinhoto líquido, na proporção de 1:20 pode elevar o seu $\mathrm{pH}$ de 5,0 para valores ao redor de 12,0 . No entanto, isto não ocorreu quando se aplicou cal nos criadouros, dada a grande dificuldade de se atingir homogeneamente os $10 \mathrm{~cm}$ superficiais de solo impregnado. Em várias tentativas, utilizando-se diferentes formas de aplicação e diferentes dosagens, não se conseguiu elevar o pH além de 8,7, que mostrou não ser limitante para o desenvolvimento larval.

A escolha da mistura Cal/Bórax é decorrência da urgência que a empresa tem em controlar a população de moscas. À medida que foram sendo evidenciados alguns aspectos da dinâmica dos focos, foram sendo testadas técnicas já aprovadas em controle de focos larvais de moscas em outras regiões. Entre os vários produtos utilizados como larvicidas, fora do grupo de inseticidas sintéticos, o Bórax aparece tradicionalmente como o que melhores efeitos apresenta (Cook \& Hutchison, 1916; Cook, Hutchison \& Scales, 1914; Bishopp, 1939). Em virtude do seu baixo custo, baixa toxicidade, e por ser normalmente necessário à complementação mineral da lavoura, desde que respeitadas as proporções de um micro-nutriente, não acarreta preocupação quando 


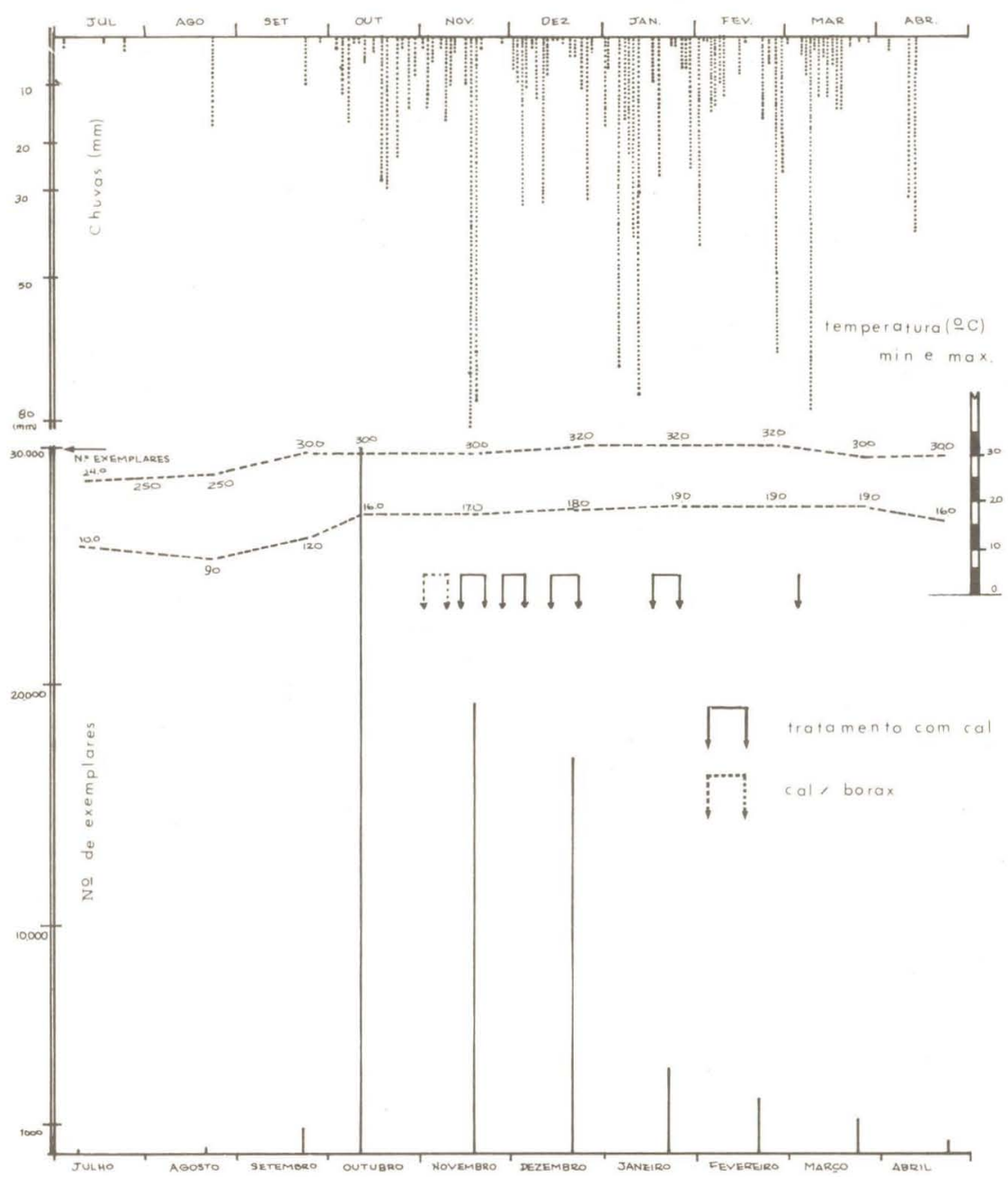

Figura 1. Variação da densidade de moscas em função da temperatura e tratamento dos focos. Macatuba, S. Paulo 1981/1982.

aplicado apenas nas áreas de manejo da vinhaça, principalmente após o término da fertirrigação.

Como já se observou anteriormente, precipitações ao redor de $70 \mathrm{~mm}$ determinam alta mortalidade nos criadouros. Observou-se porém que, 20 dias após uma chuva forte, os criadouros já apresentam intensa atividade larval.

Observou-se que aplicações sistemáticas da mistura Cal/Bórax, na totalidade dos criadouros, pode reduzir a densidade e mantê-la a níveis baixos por longo período de tempo, como ocorreu no perído de janeiro a março.

Acredita-se que o tratamento deva ser realizado visando manter a densidade baixa nos intervalos entre as grandes chuvas, elemento natural de controle da população, quando os criadouros estão confinados às valas e tanques de manejo de vinhaça. 


\section{AGRADECIMENTOS}

Agradecemos aos Drs. José Luiz Corbini e José Marcos Lorenzetti, da Usina São José (Zillo-Lorenzetti), Macatuba, SP, pela ajuda prestada na realização deste trabalho.

\section{REFERENCIAS}

Anon., 1981. Foco de moscas em Araraquara é lagoa de restilo. Folha de $S$ Paulo 05.xi.1981: 17.

Bishopp, F. C., 1939. Housefly control. U. S. Dep. Agric. Leafl. 182: 1-6, 5 figs.

Capozoli, V., 1981. Canaviais desequilibram a ecologia em Ribeirão Preto. Folha de S Paulo 13.xii.1981: 28.

Cook, F. C. \& R. H. Hutchison, 1916. Experiments during 1915 in destruction of fly larvae in horse manure. Bull. U. S. Dep. Agric. 408: 1-19.

Cook, F. C., Hutchison, R. H. \& F. M. Scales, 1914. Experiments in the destruction of fly larvae in horse manure. Ibid. 118: 1-26, 4 pls.

Copersucar, 1980. Relatório das atividades. São Paulo.

Glória, N. A., 1977. Utilização da vinhaça na cultura da cana-de-açúcar. Res. 29. a Reun. SBPC, S Paulo.

Governo do Estado de São Paulo, 1980. Decreto n. ${ }^{\circ} 16.162$, de 19 de novembro de 1980: Institui o Programa do Vinhoto e Pró-Vinhoto e dá providências correlatas. Diário Oficial, S Paulo 20.xi.1980: 4.

West, L. S. \& O. B. Peters, 1973. An annotated bibliography of Musca domestica, 743 pp. Northern Michigan University, Marquette, Mich. 